\title{
Estimation of Blood Loss in Oral and Maxillofacial Surgery by Measurements of Low Haemoglobin Levels in Mixtures of Blood, Saliva and Saline: a Laboratory Study
}

\author{
Krister Johansson $^{1,2}$, Martin Lindström ${ }^{1}$, Manaf Alhabshi ${ }^{1}$, Marianne Ahmad ${ }^{1}$, Peter J. Svensson ${ }^{3}$, \\ Jonas P. Becktor ${ }^{1}$ \\ ${ }^{1}$ Department of Oral and Maxillofacial Surgery and Oral Medicine, Faculty of Odontology, Malmö University, Malmö, \\ Sweden. \\ ${ }^{2}$ Department of Oral \& Maxillofacial Surgery, Skåne University Hospital, Lund, Sweden. \\ ${ }^{3}$ Department of Translational Medicine, Clinical Coagulation Research Unit, Skåne University Hospital, Malmö, Sweden.
}

\author{
Corresponding Author: \\ Krister Johansson \\ Department of Oral and Maxillofacial Surgery and Oral Medicine \\ Faculty of Odontology, Malmö University \\ SE-20506, Malmö \\ Sweden \\ Phone: +46406658485 \\ Fax: +46406658439 \\ E-mail: krister.johansson@mau.se
}

\begin{abstract}
Objectives: Estimating blood loss is an important factor in several surgical procedures. The accuracy of blood loss measurements in situations where blood is mixed with saliva and saline is however uncertain. The purpose of this laboratory study was to ascertain if blood loss measurements in mixtures of blood, saline, and saliva are reliable and could be applicable in a clinical setting.

Material and Methods: Venous blood and resting saliva were collected from six volunteers. Saliva, saline, and combinations thereof were mixed with blood to obtain different concentrations. A portable spectrophotometer was first used to measure the haemoglobin concentration in undiluted venous blood followed by measurements of the haemoglobin concentration after each dilution. To examine the strength of linear relationships, linear regression and Pearson correlations were used.

Results: The measurements of haemoglobin concentrations in mixtures of blood, saline, and saliva were proven to be accurate for haemoglobin measurements $>0.3 \mathrm{~g} / \mathrm{dl}$ (correlation $=0.986$ to 1 ). For haemoglobin measurements $<0.3 \mathrm{~g} / \mathrm{dl}$, a small increase in haemoglobin values were reported, which was directly associated to the saliva concentration in the solution (correlation $=0.983$ to 1 ). This interference of saliva was significantly eliminated by diluting the samples with saline, mimicking the clinical situation.

Conclusions: The results suggest that a portable spectrophotometer can be used clinically to preoperatively measure the haemoglobin value of a venous blood sample and postoperatively measure the haemoglobin value of the collected liquids, including shed blood, thereby achieving a highly accurate method of measuring blood loss during oral and maxillofacial surgery.
\end{abstract}

Keywords: oral surgery; postoperative hemorrhage; saliva; surgical blood loss.

\footnotetext{
Accepted for publication: 25 June 2021

To cite this article:

Johansson K, Lindström M, Alhabshi M, Ahmad M, Svensson PJ, Becktor JP.

Estimation of Blood Loss in Oral and Maxillofacial Surgery by Measurements of Low Haemoglobin Levels in Mixtures of Blood, Saliva and Saline: a Laboratory Study

J Oral Maxillofac Res 2021;12(2):e3

URL: http://www.ejomr.org/JOMR/archives/2021/2/e3/v12n2e3.pdf

doi: $10.5037 /$ jomr.2021.12203
} 


\section{INTRODUCTION}

Peri- and postoperative blood loss in oral and maxillofacial surgery (OMFS) is seldom a clinical problem but under certain circumstances major haemorrhage may occur. Multiple measurements like pulse, cutaneous vasoconstriction, urinary output, and estimated blood loss are important factors to detect hypovolemia and initiate fluid management such as transfusion [1]. Various methods are available to estimate the amount of blood loss during different surgeries $[\underline{2}, \underline{3}]$. However, the data on monitoring blood loss during OMFS is rather limited. There are published studies on relatively rough estimations of blood loss in OMFS performed by weighing surgical gauze swabs and measuring the contents after deducting the saline from the total volume of the suction bottle $[\underline{4}, \underline{5}]$.

Another method for monitoring blood loss that may be useful during OMFS is to calculate the blood loss by multiplying the total volume of the liquid collected in the suction bottle by its haemoglobin value, and then divide the product by the haemoglobin value from a preoperatively collected venous blood sample of the patient $[\underline{6}, 7]$. To facilitate the procedure, a portable device for haemoglobin measurements may be used. The HemoCue ${ }^{\circledR}$ system (HemoCue AB; Ängelholm, Sweden), is a compact device that provides an immediate haemoglobin measurement from a small blood volume deposited to a disposable cuvette [ $\underline{8}]$. The HemoCue ${ }^{\circledR}$ system has been compared with other spectrophotometric devices and has shown a high accuracy regarding haemoglobin concentration measurements $[\underline{8}, 9]$. Spectrophotometry in general has been proven quite accurate in measurements of the haemoglobin concentration in blood but in OMFS, where blood is often diluted due to the saline irrigation and saliva, it could be difficult with the current systems to accurately measure haemoglobin concentrations [10]. To overcome these difficulties, the HemoCue ${ }^{\circledR}$ Plasma/Low $\mathrm{Hb}$ system has been developed and has been proven to accurately measure haemoglobin levels in low blood concentrations [1113]. However, to the best of our knowledge, neither the Hemocue ${ }^{\circledR}$ system nor other devices intended to measure haemoglobin levels have been tested on blood diluted with saliva. Hence, the aim of the present study was to, in a laboratory model, validate haemoglobin measurements in diverse mixtures of blood, saliva, and saline using a Hemocue ${ }^{\circledR}$ haemoglobin system and thereby test the hypothesis that saline and saliva would not influence the results of the measurements.

\section{MATERIAL AND METHODS Population}

Blood and saliva were collected from six healthy volunteers (donor 1 - 6), two males and four females, aged from 26 to 64 . The subjects were divided into groups. Five participants (donor 1, 2, 4 - 6) were included in the preparatory test were different concentrations of saliva were analyzed with both devices. Three subjects (donor 1 - 3) underwent measurements of different combinations of blood and saliva with the $\mathrm{HemoCue}^{\circledR} \mathrm{Hb} \mathrm{201^{+ }}$ system and three subjects (donor 2 - 4) underwent the analyses of various concentrations of blood and saliva with the HemoCue ${ }^{\circledR}$ Plasma/Low Hb system. Recruitment was done among the staff at the department were the study was conducted and informed consent was obtained from all individual participants. The study was conducted from 5 May, 2017 to 28 June, 2017 at the Department of Oral and Maxillofacial Surgery and Oral Medicine, Faculty of Odontology, Malmö University, Malmö, Sweden. The study was approved by the by the Ethical Review Board in Lund, Sweden on 12 May, 2016 (Dnr. 2016/286) and has been performed according to the general principles of the Declaration of Helsinki (General Assembly, Helsinki, Finland, June 1964), on ethical principles for medical research involving human subjects.

\section{Blood and saliva collection}

Blood and saliva samples were collected 1 to 2 hours before implementation of the experiments and stored at room temperature $\left(22\right.$ to $\left.25^{\circ} \mathrm{C}\right)$. Blood was collected through venepuncture into evacuated tubes containing K2 EDTA (BD Vacutainer ${ }^{\circledR}$ Plus Plastic $\mathrm{K}_{2}$ EDTA tubes - Becton, Dickinson and Co.; Franklin Lakes, New Jersey, USA) [14]. Resting saliva was collected in sterile tubes by spitting. Before collection of saliva the donors were asked to thoroughly rinse the mouth. The tubes were stored on a tube rocker after collection and during the experiments in order to achieve homogeneity of the samples. Before utilisation of saliva, foam was removed from the tubes to enable correct volume measurements. One blood sample and one tube of saliva were collected from each participant.

\section{Assay methods}

$\mathrm{HemoCue}^{\circledR} \mathrm{Hb} 201^{+}$system and HemoCue ${ }^{\circledR}$ Plasma/ Low $\mathrm{Hb}$ system and microcuvettes recommended by the manufacturer were used for analysing haemoglobin 
concentrations in diverse mixtures of blood, saliva, and saline. Both devices are factory-calibrated against the International Council for Standardization in Haematology (ICSH) reference method. The reaction in the microcuvettes is a modified azidmethaemoglobin reaction. The erythrocyte membranes are disintegrated by sodium deoxycholate and haemoglobin is released. Sodium nitrite transforms haemoglobin into methaemoglobin, which combines with sodium azide to form azidemethaemoglobin. To correct for turbidity, two wavelengths $(570 \mathrm{~nm}$ and 880 $\mathrm{nm})$ are used for the absorbance measurements. All analyses were performed in an accredited laboratory (Skåne County Council, Office for Medical Services, Division of Laboratory Medicine, Department of Clinical Chemistry, Section of Special Chemistry, Unit of Malmö) with validated instruments at room temperature. To avoid potential immunological reactions, blood and saliva from different individuals were not mixed.

As a preparatory test, saliva from five subjects (donor 1, 2, 4 - 6) was diluted with saline to saliva concentrations of $100 \%, 75 \%, 50 \%, 25 \%$ and $12.5 \%$ and analysed to evaluate any impact on the HemoCue ${ }^{\circledR}$ $\mathrm{Hb} 201^{+}$system and the HemoCue ${ }^{\circledR}$ Plasma/Low $\mathrm{Hb}$ system of saliva only.

According to the manufacturer, the intended use for $\mathrm{HemoCue}^{\circledR} \mathrm{Hb} 201^{+}$system is quantitative determination of haemoglobin in whole blood within the measuring range from 0 to $25.6 \mathrm{~g} / \mathrm{d}$ l. Three different liquids were prepared: one reference/ golden standard solution containing saline only; one containing a mixture of equal amounts of saliva and saline (50/50) and one solution containing saliva. The prepared liquids were poured into several test tubes and, when applicable, mixed with blood to final blood concentrations of $0 \%, 25 \%, 50 \%$ and $75 \%$. These samples and samples containing $100 \%$ blood were analysed.

According to the manufacturer, HemoCue ${ }^{\circledR}$ Plasma/ Low $\mathrm{Hb}$ system is designed for quantitative determination of low levels of haemoglobin in plasma, serum, and aqueous solutions. Based on calculations of normal salivary flow, estimated duration of OMFS interventions and average volume of saline used during dento-alveolar surgery three different liquids were prepared: one reference/golden standard solution containing saline only, one containing saliva $12.5 \%$ / saline $87.5 \%$ and one solution containing saliva only [15-17]. The HemoCue ${ }^{\circledR}$ Plasma/Low Hb system is linear and calibrated for measurements between 0.03 and $3 \mathrm{~g} / \mathrm{dl}$. Consequently, to achieve haemoglobin levels within this range, each one of the 3 mixtures was poured into several test tubes and mixed with blood to final blood concentrations of $0.4 \%, 0.8 \%$, $2.4 \%, 7.6 \%$ and $15.2 \%$.

To analyse the samples obtained from the experiments, each liquid was thoroughly mixed and then a drop of the solution was placed on a hydrophobic clean surface. A microcuvette was then filled according to the instruction for use and analysed within a minute. This was repeated five times for each sample. Previous to any series of measurement each system was checked using quality control solutions obtained from the manufacturer.

\section{Statistical analysis}

To examine the strength of linear relationships of the samples containing blood in different concentrations, linear regression and Pearson and Spearman's correlations were used. For both the HemoCue ${ }^{\circledR}$ $\mathrm{Hb} 201^{+}$system and the HemoCue ${ }^{\circledR}$ Plasma/Low $\mathrm{Hb}$ system the haemoglobin values retained from the measurements of the series of blood samples diluted with saline only, saliva only or a mixture of saline and saliva were compared. The samples from different donors were not compared with each other due to variances in blood and saliva composition. For the HemoCue ${ }^{\circledR}$ Plasma/Low Hb system the limits of detection (LOD) were calculated. Analyses were performed using Microsoft Office Excel 2013 program (Microsoft Corporation, Redmond, Washington, USA) and figures were produced in SPSS Statistics version $25\left(\mathrm{IBM}^{\circledR}\right.$, Chicago, Illinois, USA).

\section{RESULTS \\ Whole blood system $\left(\mathrm{HemoCue}^{\circledR} \mathrm{Hb} \mathrm{201}^{+}\right.$)}

For every single donor, the values from the different measurements correlated well, hence the $\mathrm{HemoCue}^{\mathbb{B}}$ $\mathrm{Hb} 201^{+}$system did not react either on saliva from five

Table 1. Analyses of saliva diluted in saline only

\begin{tabular}{l|c|c|c|c|c}
\hline Donor & $\mathbf{1}$ & $\mathbf{2}$ & $\mathbf{4}$ & $\mathbf{5}$ & $\mathbf{6}$ \\
\hline Whole blood system & Results not elevated & Results not elevated & Results not elevated & Results not elevated & Results not elevated \\
\hline Low haemoglobin system & $25 \%$ & $75 \%$ & $25 \%$ & $50 \%$ & $50 \%$ \\
\hline
\end{tabular}

Description of the lowest saliva concentration required ( 0 to $100 \%$ ) to get elevated results ( $>0 \mathrm{~g} / \mathrm{dL}$ ) from the analyses. Saliva 0 to $100 \%$ did not affect the whole blood measurement device. Saliva 25 to $75 \%$ or more affected the low haemoglobin device. 
Table 2. Analyses made with the whole blood system of blood diluted with saliva and/or saline

\begin{tabular}{l|c|c|c|c|c|c|c|c|c}
\hline Donor & \multicolumn{3}{|c|}{$\mathbf{1}(\mathbf{n}=\mathbf{2 5})$} & \multicolumn{3}{c|}{$\mathbf{2}(\mathbf{n}=\mathbf{2 5})$} & \multicolumn{3}{c}{$\mathbf{3}(\mathbf{n}=\mathbf{2 5})$} \\
\hline Diluent & Saline & $\begin{array}{c}\text { Saline 50\%, } \\
\text { saliva 50\% }\end{array}$ & Saliva & Saline & $\begin{array}{c}\text { Saline 50\%, } \\
\text { saliva 50\% }\end{array}$ & Saliva & Saline & $\begin{array}{c}\text { Saline 50\%, } \\
\text { saliva 50\% }\end{array}$ & Saliva \\
\hline $\begin{array}{l}\text { Spearman's rank } \\
\text { correlation }\end{array}$ & 0.991 & 0.99 & 0.989 & 0.989 & 0.991 & 0.99 & 0.989 & 0.988 & 0.986 \\
\hline Pearson correlation & 1 & 1 & 1 & 1 & 1 & 0.998 & 1 & 0.999 & 1 \\
\hline Slope & 0.157 & 0.157 & 0.157 & 0.13 & 0,13 & 0.13 & 0.137 & 0.138 & 0.137 \\
\hline Y-intercept & -0.12 & -0.076 & -0.084 & -0.076 & -0.052 & 0.028 & -0.036 & -0.024 & -0.096 \\
\hline
\end{tabular}

Blood was diluted with either saline only (reference/golden standard), saline $50 \%$ /saliva $50 \%$ or saliva only.

For every single donor, the values from the different measurements showed a high degree of correlation, reflecting that saliva did not have any impact on the measurements.

subjects (donor 1, 2, 4-6) in different concentrations diluted with saline (Table 1) or on series of samples from donor 1 - 3 containing blood mixed with saliva and/or saline, except for isolated outliers when blood was diluted with saliva only (Table 2, Figure 1).

\section{Low haemoglobin system $\left(\mathrm{HemoCue}{ }^{\circledR}\right.$ Plasma/Low Hb)}

Saliva from five subjects (donor 1, 2, 4 - 6) diluted with saline only was analysed, showing that the $\mathrm{HemoCue}^{\circledR}$ Plasma/Low $\mathrm{Hb}$ system reacted on saliva concentrations of more or equal to $25-75 \%$, depending on saliva donor (Table 1). Results from the series of samples from donor 2 to 4 containing blood mixed with saliva and/or saline revealed that the correlations were overall close to one and the slopes for measurements within a single donor showed high consistency. Because the intended measure range of the HemoCue ${ }^{\circledR}$ Plasma/Low Hb system is close to zero $(0.03$ to $3 \mathrm{~g} / \mathrm{dl})$, the trend of differences in Y-intercept observed within the measurements from every donor could therefore be used as a measurement of the impact of saliva (Table 3). The more saliva a blood sample contained the higher were the haemoglobin levels reported from the $\mathrm{HemoCue}^{\circledR}$ Plasma/Low $\mathrm{Hb}$ system, given that the blood concentration was unaltered and that the blood came from the same donor (Figure 2). Limits of detection for the $\mathrm{HemoCue}^{\circledR}$ Plasma/Low $\mathrm{Hb}$ system were in the range of 0.03 to $0.1 \mathrm{~g} / \mathrm{dl}$, and thus quite concordant with the information stated by the manufacturer (the system should be linear between 0.03 and $3 \mathrm{~g} / \mathrm{dl}$ ).

\section{DISCUSSION}

The present study investigated how haemoglobin measurements were affected by various mixtures of blood, saliva, and saline. The results suggested that haemoglobin analyses made with a whole blood measurement device were not influenced by saliva when compared to reference samples diluted with saline. When measuring haemoglobin with a spectrophotometer developed for low haemoglobin measurements, a slight increase in the reported haemoglobin levels was observed compared to reference samples diluted with saline, especially for the combination of low blood concentrations and high saliva concentrations. These false high haemoglobin results could possibly be related to the protein phase of the saliva and the settings of the absorbance measurement device. Because the correlations for all measurements, including those of the salivadiluted samples, were close to one, one could expect that the small impact of saliva could be foreseen,

Table 3. Analyses made with the low haemoglobin system of blood diluted with saliva and/or saline

\begin{tabular}{|c|c|c|c|c|c|c|c|c|c|}
\hline Donor & & $2(n=25)$ & & & $3(n=25)$ & & & $4(n=25)$ & \\
\hline Diluent & Saline & $\begin{array}{c}\text { Saline } 87.5 \% \text {, } \\
\text { saliva } 12.5 \%\end{array}$ & Saliva & Saline & $\begin{array}{l}\text { Saline } 87.5 \% \text {, } \\
\text { saliva } 12.5 \%\end{array}$ & Saliva & Saline & $\begin{array}{c}\text { Saline } 87.5 \% \text {, } \\
\text { saliva } 12.5 \%\end{array}$ & Saliva \\
\hline $\begin{array}{l}\text { Spearman's rank } \\
\text { correlation }\end{array}$ & 0.99 & 0.983 & 0.984 & 0.987 & 0.988 & 0.988 & 0.987 & 0.986 & 0.984 \\
\hline Pearson correlation & 1 & 1 & 1 & 1 & 1 & 1 & 1 & 1 & 0.999 \\
\hline Slope & 13.261 & 13.445 & 13.051 & 12.568 & 12.437 & 12.469 & 16.271 & 16.39 & 16.118 \\
\hline Y-intercept & -0.013 & 0.007 & 0.099 & -0.006 & 0.009 & 0.05 & -0.01 & 0.011 & 0.092 \\
\hline
\end{tabular}

Blood was diluted with either saline only (reference/golden standard), saline $87.5 \% /$ saliva $12.5 \%$ or saliva only. The correlations were overall close to one and the slopes for measurements within a single donor showed high consistency. The trend of differences in Y-intercept that could be observed within the measurements from every donor reflects the impact of saliva on the measurements. 


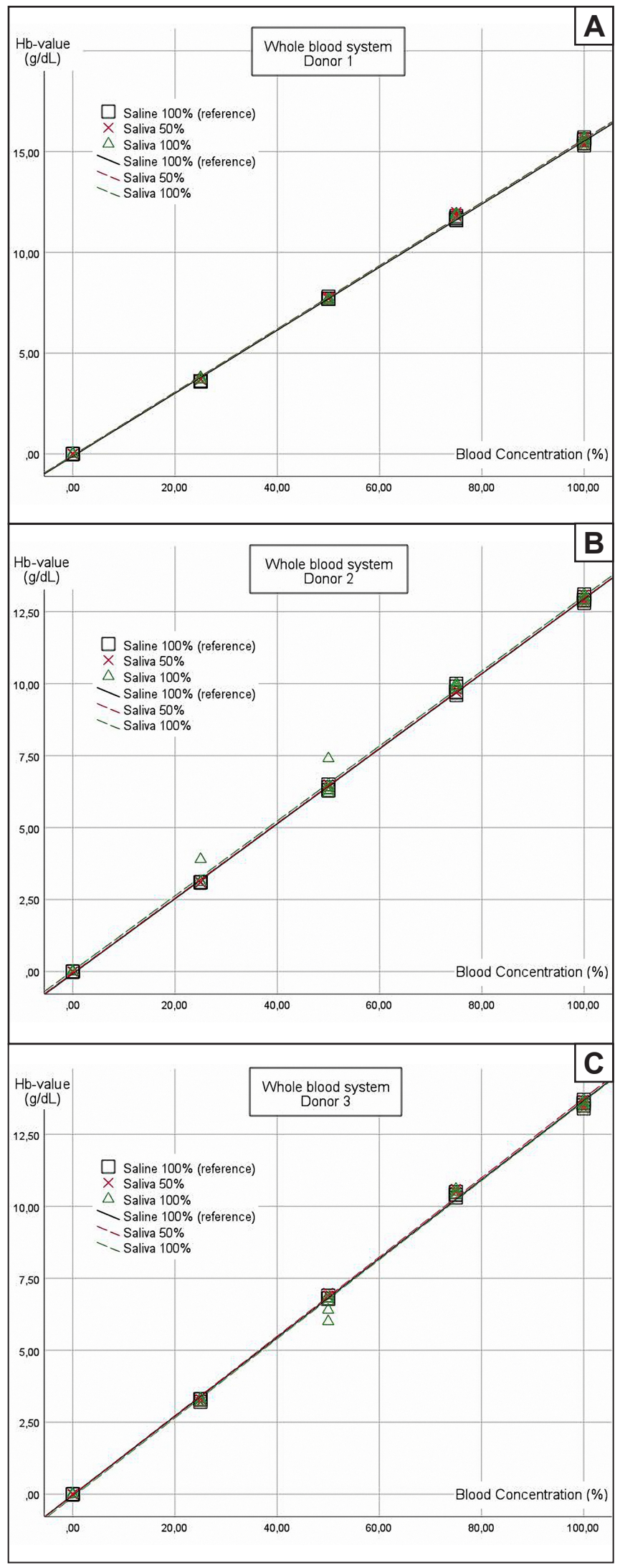

Figure 1. Retained haemoglobin values at different blood concentrations from the measurements with the whole blood system: $\mathrm{A}=$ donor $1 ; \mathrm{B}=$ donor 2 ; $\mathrm{C}=$ donor 3 .

Twenty-five measurements were done for saline $100 \%$, saliva $50 \%$ and saliva $100 \%$ each.

Not all results are distinguishable in the figure due to overlapping, indicating high correlation of the measurements.
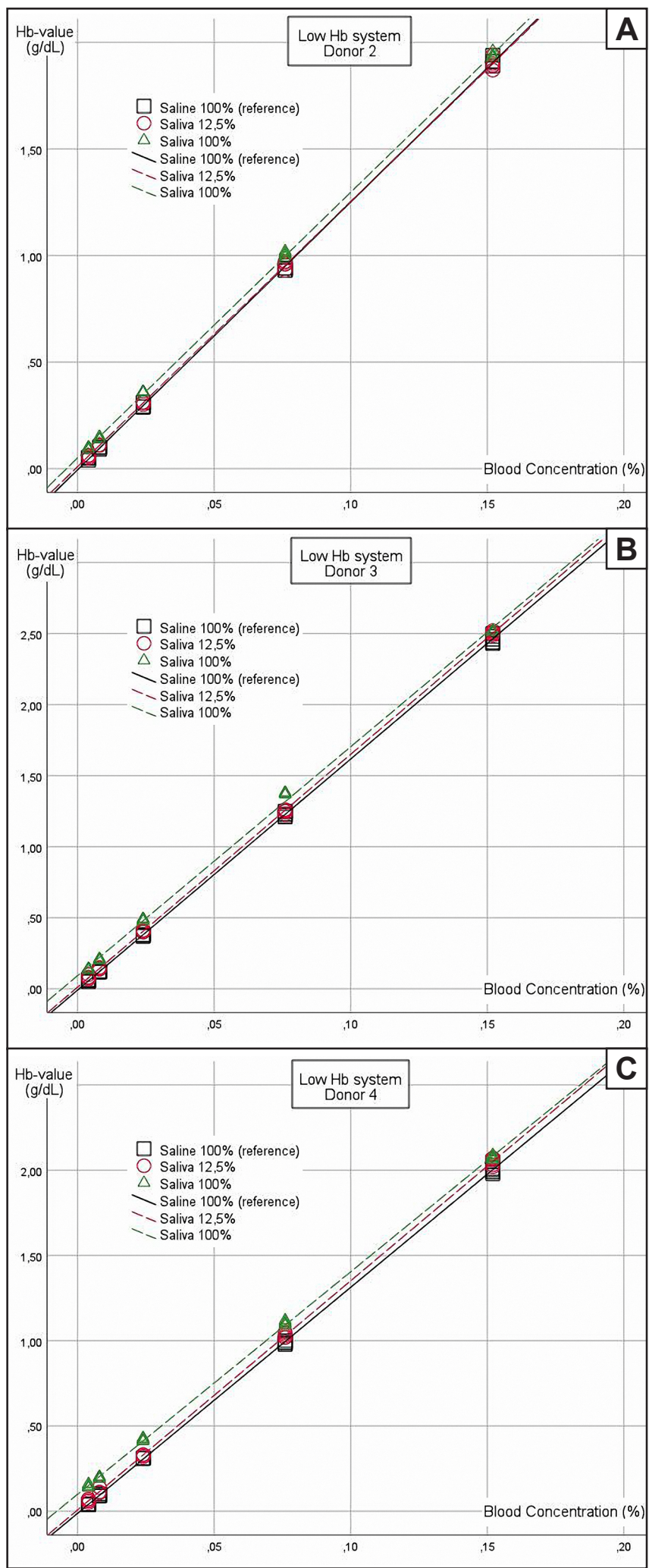

Figure 2. Retained haemoglobin values at different blood concentrations from the measurements with the low haemoglobin system: $\mathrm{A}=$ donor $2 ; \mathrm{B}=$ donor $3 ; \mathrm{C}=$ donor 4 .

Twenty-five measurements were done for saline $100 \%$, saliva $12.5 \%$ and saliva $100 \%$ each.

Not all results are distinguishable due to overlapping, indicating high correlation of the measurements. The more saliva a sample consisted of, the higher were the haemoglobin levels reported from the low haemoglobin system, given that the blood concentration was unaltered and that the blood came from the same donor. 
and thereby adjusted for. One other explanation for the fact that saliva only seemed to affect measurements performed with the device for low haemoglobin measurements could be that the HemoCue ${ }^{\circledR}$ Plasma/ Low $\mathrm{Hb}$ spectrophotometer used in the study presents data with one more decimal than the instrument used for whole blood measurements. Both devices are factory-calibrated against the International Council for Standardization in Haematology (ICSH) reference method and consequently the blood samples that were diluted with saline only to different haemoglobin concentrations (Table 2), may be used as reference values. The descriptive statistics that were used to generate the results (Table 2, Figure 1 and 2) displayed obvious linear relationships. Consequently, there was no need for any interferential statistical analysis and no P-values are presented in this study. The results from the present study could be judged as general even though the study had few participants because the correlation for all measurements were close to one.

To test if the protein phase of saliva would interfere with the measurements, resting saliva, containing more proteins than stimulated saliva, was used [15] However, during OMFS stimulated saliva might be produced and normal stimulated salivary flow is reported 0.63 to $2.94 \mathrm{ml} / \mathrm{min}[\underline{16}, \underline{17}]$. To diminish the saliva impact on haemoglobin measurements in solutions with low blood proportions (haemoglobin levels $\leq 0.3 \mathrm{~g} / \mathrm{dl}$ ), one could suggest adding saline before measurements with a HemoCue ${ }^{\circledR}$ Plasma/Low $\mathrm{Hb}$ spectrophotometer are performed.

Clinically assessment of blood loss is often based on visual estimation and subtraction of saline from the liquid collected. However, the results from the present study suggest that a portable spectrophotometer could measure haemoglobin levels with high precision even when blood is mixed with saline and saliva. This finding supports the possibility of performing accurate blood loss measurements in OMFS. The blood loss may be calculated by multiplying the total volume of the liquid collected in the suction bottle by its haemoglobin value, and then divide the product by the haemoglobin value from a preoperatively collected venous blood sample of the patient $[\underline{6}, \underline{7}]$. The total volume of the liquid in the suction canister could be visually estimated by using the reference levels marked on the canister. Another, perhaps more accurate way, of establishing the total volume of the liquid in the suction bottle is to measure the mass of the collected fluid by weighting the filled bottle after the treatment and subtracting the weight of an empty suction bottle [8]. The haemoglobin value of the liquid in the suction canister may be analysed using a portable spectrophotometer. The patient's venous haemoglobin value will exhibit minor variations during surgery due to infusion of fluids into the blood stream. These small haemoglobin changes are in most cases not expected to influence the calculation of blood loss described, and thus a preoperative venous haemoglobin value is often sufficient when calculating the blood loss [19]. But if significant blood loss has occurred and the surgery has lasted for several hours, utilisation of the mean haemoglobin value from a venous blood sample collected preoperatively and another sample collected postoperatively could be suggested in order to increase the accuracy of the calculation.

Other possible applications of the method described in this study could be measurements of bleeding tendency caused by different drugs or comparison of different haemostatic agents. It might be appropriate to perform such measurements intraorally because bleeding tendency is related to temperature [20] and the temperature of the oral cavity could be expected to show less variation than the temperature of the skin $[21,22]$. Factors influencing the measurements of the spectrophotometer such as clot formation and debris accumulation could easily be counteracted by application of anticoagulants in the solution and usage of filtering traps. A significant limitation of the clinical utility of the method is however the operator's ability to collect the entire blood loss during surgery. Making the operator aware of the need to properly collect the blood loss and to avoid the interference of blood accumulation within different sites such as surgical sponges may reduce this problem.

\section{CONCLUSIONS}

Measurements of haemoglobin concentrations using a device for whole blood measurements in mixtures of blood, saline, and saliva are reliable and comparable to measurements in mixtures of blood and saline and could be recommended for haemoglobin levels $\geq 0.3 \mathrm{~g} / \mathrm{dl}$. For haemoglobin levels $\leq 0.3 \mathrm{~g} / \mathrm{dl}$ in mixtures of blood, saline, and saliva utilisation of a spectrophotometer intended for low haemoglobin measurements could be recommended if the mixture is well diluted with saline prior to any measurements in order to diminish the saliva impact. Given these differences, it is suggested that both systems can be applied in the field of oral and maxillofacial surgery, which could improve blood loss measurements and support the surgeon and anaesthesiologist in avoiding hypovolemia and determine fluid management. 


\section{ACKNOWLEDGEMENTS AND DISCLOSURE STATEMENTS}

The authors declare that they have no conflict of interest related to this study. The authors would like to thank Dr Ryo Jimbo (Department of Oral and Maxillofacial Surgery and Oral Medicine,
Malmö University) for his help with the manuscript and Per-Erik Isberg (Department of Statistics, Lund University) for reviewing the methodology. This work was supported by Odontological Research in the Skåne Region (OFRS) grant number 746811. OFRS was not involved in study design, in the collection, analysis and interpretation of data, the writing of the report or the decision to submit the article for publication.

\section{REFERENCES}

1. Rogers SN, Horisk K, Groom P, Lowe D. Management of anaemia and blood in patients having neck dissections or free flaps for head and neck cancer. Br J Oral Maxillofac Surg. 2019 Jul;57(6):543-549. [Medline: 31128950] [doi: 10.1016/j.bjoms.2019.05.001]

2. Nowicki PD, Ndika A, Kemppainen J, Cassidy J, Forness M, Satish S, Hassan N. Measurement of Intraoperative Blood Loss in Pediatric Orthopaedic Patients: Evaluation of a New Method. J Am Acad Orthop Surg Glob Res Rev. 2018 May 8;2(5):e014. [Medline: 30211390] [PMC free article: 6132334] [doi: 10.5435/JAAOSGlobal-D-18-00014]

3. Larsen MK, Kofod T, Duch K, Starch-Jensen T. Short-term Haematological Parameters Following Surgical Removal of Mandibular Third Molars with Different Doses of Methylprednisolone Compared with Placebo. A Randomized Controlled Trial. J Oral Maxillofac Res. 2020 Jun 30;11(2):e3. [Medline: 32760476] [PMC free article: 7393928] [doi: 10.5037/jomr.2020.11203]

4. Prasant MC, Kar S, Rastogi S, Hada P, Ali FM, Mudhol A. Comparative Study of Blood Loss, Quality of Surgical Field and Duration of Surgery in Maxillofacial Cases with and without Hypotensive Anesthesia. J Int Oral Health. 2014 Nov-Dec;6(6):18-21. [Medline: 25628477] [PMC free article: 4295448]

5. Salma RG, Al-Shammari FM, Al-Garni BA, Al-Qarzaee MA. Operative time, blood loss, hemoglobin drop, blood transfusion, and hospital stay in orthognathic surgery. Oral Maxillofac Surg. 2017 Jun;21(2):259-266. [Medline: 28466191] [doi: 10.1007/s10006-017-0626-1]

6. Patel A, Goudar SS, Geller SE, Kodkany BS, Edlavitch SA, Wagh K, Patted SS, Naik VA, Moss N, Derman RJ. Drape estimation vs. visual assessment for estimating postpartum hemorrhage. Int J Gynaecol Obstet. 2006 Jun;93(3):220-4. [Medline: 16626718] [doi: 10.1016/j.ijgo.2006.02.014]

7. Guinn NR, Broomer BW, White W, Richardson W, Hill SE. Comparison of visually estimated blood loss with direct hemoglobin measurement in multilevel spine surgery. Transfusion. 2013 Nov;53(11):2790-4. [Medline: 23438094] [doi: $10.1111 / \operatorname{trf} .12119]$

8. Lamhaut L, Apriotesei R, Combes X, Lejay M, Carli P, Vivien B. Comparison of the accuracy of noninvasive hemoglobin monitoring by spectrophotometry $(\mathrm{SpHb})$ and $\mathrm{HemoCue}{ }^{\circledR}$ with automated laboratory hemoglobin measurement. Anesthesiology. 2011 Sep;115(3):548-54. [Medline: 21716091] [doi: 10.1097/ALN.0b013e3182270c22]

9. Skelton VA, Wijayasinghe N, Sharafudeen S, Sange A, Parry NS, Junghans C. Evaluation of point-of-care haemoglobin measuring devices: a comparison of Radical-7TM pulse co-oximetry, HemoCue(®) and laboratory haemoglobin measurements in obstetric patients*. Anaesthesia. 2013 Jan;68(1):40-5. [Medline: 23088815] [doi: 10.1111/anae.12039]

10. van Kampen E, Zijlstra WG. Standardization of hemoglobinometry. II. The hemiglobincyanide method. Clin Chim Acta. 1961 Jul;6:538-44. [Medline: 14453500] [doi: 10.1016/0009-8981(61)90145-0]

11. Morris LD, Pont A, Lewis SM. Use of a new HemoCue system for measuring haemoglobin at low concentrations. Clin Lab Haematol. 2001 Apr;23(2):91-6. [Medline: 11488847] [doi: 10.1046/j.1365-2257.2001.00363.x]

12. Lurie F, Jahr JS, Driessen B. The novel HemoCu plasma/low hemoglobin system accurately measures small concentrations of three different hemoglobin-based oxygen carriers in plasma: hemoglobin glutamer-200 (bovine) (Oxyglobin), hemoglobin glutamer-250 (bovine) (Hemopure), and hemoglobin-Raffimer (Hemolink). Anesth Analg. 2002 Oct;95(4):870-3, table of contents. [Medline: 12351259] [doi: 10.1097/00000539-200210000-00014]

13. Janatpour KA, Paglieroni TG, Crocker VL, DuBois DJ, Holland PV. Visual assessment of hemolysis in red blood cell units and segments can be deceptive. Transfusion. 2004 Jul;44(7):984-9. [Medline: 15225237] [doi: 10.1111/j.1537-2995.2004.03315.x]

14. Banfi G, Salvagno GL, Lippi G. The role of ethylenediamine tetraacetic acid (EDTA) as in vitro anticoagulant for diagnostic purposes. Clin Chem Lab Med. 2007;45(5):565-76. [Medline: 17484616] [doi: 10.1515/CCLM.2007.110]

15. Schipper RG, Silletti E, Vingerhoeds MH. Saliva as research material: biochemical, physicochemical and practical aspects. Arch Oral Biol. 2007 Dec;52(12):1114-35. [Medline: 17692813] [doi: 10.1016/j.archoralbio.2007.06.009]

16. Muddugangadhar BC, Sangur R, Rudraprasad IV, Nandeeshwar DB, Kumar BH. A clinical study to compare between resting and stimulated whole salivary flow rate and $\mathrm{pH}$ before and after complete denture placement in different age groups. J Indian Prosthodont Soc. 2015 Oct-Dec;15(4):356-66. [Medline: 26929540] [PMC free article: 4762355] [doi: 10.4103/0972-4052.164907] 
17. Shimazaki Y, Fu B, Yonemoto K, Akifusa S, Shibata Y, Takeshita T, Ninomiya T, Kiyohara Y, Yamashita Y. Stimulated salivary flow rate and oral health status. J Oral Sci. 2017 Mar 31;59(1):55-62. [Medline: 28049967] [doi: 10.2334/josnusd.16-0372]

18. Vitello DJ, Ripper RM, Fettiplace MR, Weinberg GL, Vitello JM. Blood Density Is Nearly Equal to Water Density: A Validation Study of the Gravimetric Method of Measuring Intraoperative Blood Loss. J Vet Med. 2015;2015:152730. [Medline: 26464949] [PMC free article: 4590883] [doi: 10.1155/2015/152730]

19. Faverani LP, Ramalho-Ferreira G, Fabris AL, Polo TO, Poli GH, Pastori CM, Marzola C, Assunção WG, GarciaJúnior IR. Intraoperative blood loss and blood transfusion requirements in patients undergoing orthognathic surgery. Oral Maxillofac Surg. 2014 Sep;18(3):305-10. [Medline: 23620250] [doi: 10.1007/s10006-013-0415-4]

20. Mitrophanov AY, Rosendaal FR, Reifman J. Computational analysis of the effects of reduced temperature on thrombin generation: the contributions of hypothermia to coagulopathy. Anesth Analg. 2013 Sep;117(3):565-74. [Medline: 23868891] [doi: 10.1213/ANE.0b013e31829c3b22]

21. Erenberk U, Torun E, Ozkaya E, Uzuner S, Demir AD, Dundaroz R. Skin temperature measurement using an infrared thermometer on patients who have been exposed to cold. Pediatr Int. 2013 Dec;55(6):767-70. [Medline: 23927418] [doi: 10.1111/ped.12188]

22. Volchansky A, Cleaton-Jones P. Variations in oral temperature. J Oral Rehabil. 1994 Sep;21(5):605-11. [Medline: 7996344] [doi: 10.1111/j.1365-2842.1994.tb01175.x]

\section{To cite this article:}

Johansson K, Lindström M, Alhabshi M, Ahmad M, Svensson PJ, Becktor JP.

Estimation of Blood Loss in Oral and Maxillofacial Surgery by Measurements of Low Haemoglobin Levels in Mixtures of Blood, Saliva and Saline: a Laboratory Study

J Oral Maxillofac Res 2021;12(2):e3

URL: http://www.ejomr.org/JOMR/archives/2021/2/e3/v12n2e3.pdf

doi: $\underline{10.5037 / \text { jomr.2021.12203 }}$

Copyright $@$ C Johansson K, Lindström M, Alhabshi M, Ahmad M, Svensson PJ, Becktor JP. Published in the JOURNAL OF ORAL \& MAXILLOFACIAL RESEARCH (http://www.ejomr.org), 30 June 2021.

This is an open-access article, first published in the JOURNAL OF ORAL \& MAXILLOFACIAL RESEARCH, distributed under the terms of the Creative Commons Attribution-Noncommercial-No Derivative Works 3.0 Unported License, which permits unrestricted non-commercial use, distribution, and reproduction in any medium, provided the original work and is properly cited. The copyright, license information and link to the original publication on (http://www.ejomr.org) must be included. 